\title{
COGNITIVE IMPLEMENTATION OF \\ INCONGRUENT L2/C2 PEDAGOGIES IN TERTIARY \\ EDUCATION. TEACHING ENGLISH LITERATURE \\ TO SPANISH UNDERGRADUATE STUDENTS IN SPAIN HOSTING L2 CONCEPTUAL METAPHORS ${ }^{1}$
}

\author{
Juani Guerra, \\ Cognition and Cultural Health Laboratory (LabCSC-IUIBS-ULPGC), \\ University of Las Palmas de Gran Canaria \\ Email: juani.guerra@olpgc.es
}

Received: November 16, 2020

Accepted: December 8, 2020

\begin{abstract}
This paper explores and evaluates a novel theoretical foundation and method for teaching unconventional/experimental literary texts in a non-native language. The case study described explores the crosslinguistic and crosscultural conditions in which Spanish undergraduates understand the way English experimental writers think, during tasks of reading $17^{\text {th }}$ or $20^{\text {th }} \mathrm{c}$. English texts from the Enlightenment, Modernism, and Postmodernism. Intercultural as well as translational and interlingual situations, and breakage/disruption of cognitive processes of the reader will be outlined. So far, related Spanish academic practices have mostly relied on unidirectional conduit and transmission metaphors (Reddy 1979), thus breaking the conceptual, linguistic, and cultural organization of original texts that further artfully break the organization of ordinary English language to enhance the reader's perception of other living minds and experiences. Both Cognitive Poetics (from Tsur 2002) and its more dynamicist extension Biopoetics (Guerra 2013, 2016) seem to be a true-to-life methodological framework for a unifying reading of texts from different cultures, times and genres.
\end{abstract}

Keywords: Biopoetics, cognitive poetics, enactive knowledge, metaphor, teaching method in second language, literary texts.

Resumen: Este artículo explora y evalúa una base teórica y un método novedosos para la enseñanza de textos literarios no convencionales/experimentales en un idioma no

1 The present investigation was financed by the Agencia Canaria de Investigación, Innovación y Sociedad de la Información (ACIISI) through Project C200801000234. 
El estudio de caso descrito explora las condiciones translingüísticas y transculturales en las que los estudiantes españoles entienden a través de tareas de lectura la forma de pensar de los escritores experimentales ingleses del siglo XVII o XX mediante textos en inglés de la Ilustración, el Modernismo y el Postmodernismo. Se describirán situaciones interculturales así como traslacionales e interlingüísticas, y la ruptura/interrupción de los procesos cognitivos del lector. Hasta ahora, las prácticas académicas relacionadas con el español se han basado principalmente en metáforas unidireccionales de conducto y de transmisión (Reddy 1979), rompiendo así la organización conceptual, lingüística y cultural de los textos originales que, yendo más allá, rompen la organización artística del idioma inglés común para mejorar la percepción del lector de otras mentes y experiencias vivientes. Tanto la Poética Cognitiva (de Tsur 2002) como su extensión más dinamista, la Biopoética (Guerra 2013, 2016), pueden considerarse un marco metodológico real para una lectura unificadora de textos de diferentes culturas, épocas y géneros.

Palabras clave: Biopoética, poética cognitiva, conocimiento enactivo, metáfora, método de enseñanza en segunda lengua, textos literarios.

"Turn him to any cause of policy, The Gordian Knot of it he will unloose, Familiar as his garter"

(Shakespeare, Henry V, Act 1 Scene 1)

\section{USING COGNITIVE SCIENCES IN A NON-NATIVE LITERATURE CLASS. INTRODUCTION TO THE NEW COGNITIVE HUMANITIES}

Working on the cognitive principle that the linguistic sign becomes a symbol oriented to the generation of meaning structure as concepts, current Cognitive Sciences arise as a new paradigmatic network where traditionally separated areas of knowledge converge. Cognitive Science therefore appears as a junction between the Human Sciences and the Natural Sciences, given that it includes in the same composite of study such fields as Linguistics, Poetics, Psychology, Anthropology, Philosophy, Artificial Intelligence or Neuroscience, among many others. Hence, we often speak of Cognitive Sciences (in plural), on account of the primarily crossdisciplinary nature of this approach. In fact, it would not be possible to speak of Cognitive Sciences if we were to take out this interdisciplinary perspective. This perspective benefits any attempt to find out new congruent pedagogies in the framework of the highly interactive cultural and academic environment of students in the new European Space for Higher Education (ESHE).

Under this methodology, all disciplines integrating the cognitive paradigm are likely to benefit from the results obtained in their sister branches. Before the emergence of the cognitive approach, it was the case that each object of study was explored in an isolated way, which prevented researchers to enrich their work with the scientific advances that 
other disciplines had already developed on the same topics. Consequently, it also prevented educators to pragmatically project it to the field of Education. Our present investigation applies this cognitive methodology to the teaching and learning of unconventional literary texts in a non-native language.

\subsection{Configuration of the Real World Across Different Linguistic and Cultural Communities. Case Study}

From a general view of human cognition as human action, we are concerned here with a difficult cultural situation, the L1 Spanish learning process of a L2 experimental English literary text from Enlightenment, Modernism and Postmodernism. Educationally, we are concerned with a pedagogical situation in Spain that remains unexplored: prolific bodies of data prompting an incongruent crosscultural way in which Spanish students at the University read/understand the way English experimental writers think from their written texts. At first sight, this is due to the lack of a new observational category like current Cognitive Sciences and to a traditional Spanish academic practice that has been so far communicatively established mostly on unidirectional conduit and transmission metaphors, first identified by Reddy (1979). These are metaphors underlying everyday references to communication showing wrong dynamics of containment in the conceptualization of learning. The core ideas framing this incongruent academic practice in Spain are epistemologically and phenomenologically antagonistic to the literary experimental L2/C2 constructions taught in class, literally that language works as a conduit transferring thoughts from one individual to another; that writers and speakers insert their thoughts or feelings into words; that words act as containers conveying thoughts and feelings to others; or that listeners and readers extract the thoughts and feelings from such words. These cognitive dynamics are reflected in the use of 'transferring', 'insert', 'extract', and further in the online unintentional activation of literal translations into L1 of the L2 linguistic constructions. This conduit metaphor is doubly unproductive during the teaching/learning process of an experimental English literary text to undergraduate Spanish students for whom the implicit, common sense model of communication is thus a transmission model. It's been previously studied how Spanish students are subject to all of the limitations of these models (Nuez-Placeres, G, Petersen, C. \& Guerra, J., and several other contributions in Bretones Callejas et al. eds., 2009), which still today embody most current pedagogical habits in English Literary Studies (ELS) in the Spanish University. So far invisible to researchers, these L2/C2 bodies of data, considered as sociocognitive conceptual and cultural constructions, are been lately discovered as far richer and more revealing for the evolution of teaching/learning enquiry than our efforts as educators have been able to notice. After the cognitive turn of the 1990s there have been new definitions for language and culture to implement L2/C2 teaching processes from Michel Achard \& Susanne Niemeiern (2004). Still, they basically represent linguistic systems, texts, as if they were not complex adaptive systems of online poiesis (Hayles, 1991; Guerra, 1992, 2016; Bernárdez 2008a,b), thus overlooking the basic social element taking part in this fundamentally creative conceptualization process which is the 
embodied, situated, distributed, synergic and dissipative emergence (Guerra, 2013) of meaning structure. ${ }^{2}$

\section{EXPLORING THE CROSSLINGUISTIC AND CROSSCULTURAL CONDITIONS IN WHICHSPANISH UNDERGRADUATES UNDERSTAND THE WAY ENGLISH EXPERIMENTAL WRITERS THINK}

In this section we will set out the main features of our case study and why experimental texts are particularly interesting, challenging and important for the theory of teaching and learning. The key question, how is a L2/C2 experimental literary text socioculturally situated by a L1/C1 undergraduate student, will be framed in how do text and student situate each other.

Our case study aims at affording these L2 students a first and theoretically unpretentious cognitive-conceptual and cultural 'real' experience of this L1 creative process during their online enactivation of a highly complex narrative artful L2 text. In any L2 Literary Studies focused on Second-Generation Cognitive experientialist postulates (founded during the 1980s by Lakoff, Johnson, Langacker, Fillmore, etc.), each student's pragmatic level of embodiment, understood as the bodily or material basis for mind, cognition and meaning (Ziemke, 2007: 167), is highly significant to frame and learn literary and linguistic innovations in the evolution of different literary movements. However, so far this primary pedagogical level has not been explored in the framework of Cognitive Sciences, languages and cultures, in relation to the crosscultural way Spanish students of English understand these highly difficult literary texts. This research void is the main reason why in this paper, though we are still dealing with the 'embodied mind', we are more interested in outlining a complementary cultural perspective as developed from 2000 in the cognitive studies of body, language and mind, known as sociocultural situatedness. "Briefly stated," states Roslyn Frank (2008:1) "sociocultural situatedness denotes the way(s) in which individual minds and cognitive processes are shaped by their being together with other embodied minds, i.e., their interaction with social and cultural structures, such as other agents, artifacts, conventions, etc. and, more particularly (...) with language itself' (1). As developed in Bernárdez (2008a) in terms of individual/collective cognition, we think that this is a realistic comprehensive grounding framework for current pedagogical methods like Problem-Based Learning (PBL), for instance. A core problem here is pinpointing how is a $\mathrm{L} 2 / \mathrm{C} 2$ experimental literary text socioculturally situated by a L1/C1 undergraduate student. This paper is the second part of an article (Guerra et al., 2009) on the way 17th-century and early 20th-century English texts (all of them highly experimental at the linguistic, conceptual, and cultural levels) can

2 Five main evolving theoretical edifices exploring functional relations between cognition, culture and language have emerged from the late 1980s that progressively identify new primary social aspects of (individual) cognitive activity. These focal theories are centered on embodied cognition (Lakoff \& Johnson, 1980), situated cognition (Zlatev, 1997), distributed cognition (Hutchins, 1995), synergic cognition (Bernárdez, 2007), and dissipative cognition (Guerra, 1992; 2001; 2013). Our hypothesis is that they can be analyzed as five universal (unifying) initial conditions of a human (socio)cognitive action corresponding to five types of biocultural processes of adaptive integration: bodily, environmental, collective, historical, and temporal. All of them are primary creative conditions in a bottom-up complex dynamics graduation scale varying from body to time as principles of chaotic-deterministic organization based upon chance and necessity. 
be understood as socioculturally situated in such L2/C2 class. To find a coherent answer to this highly complex question, our main search will start identifying the sociocognitive way Spanish University students cannot understand highly complex concepts as they were being evolutionary modified, renewed, particularly during the Enlightenment (SUBJECT, MIND, PROSE, REASON, NATURE, HUMANISM, SCIENCE, KING, GOD, AUTHOR, PROGRESS, etc.). These students' natural unawareness of the conceptual and linguistic cognitive actions performed in the on-course conceptual/linguistic/cultural construction of specific experimental English Enlightened, Modernist, and Postmodernist texts needs a first triggering of them as living systems originally embodied in a different culture and historical time. Basically, a first problem is that our students approach L2/C2 texts as closed systems that are further unnaturally constrained by the different $\mathrm{L} 1 / \mathrm{C} 1$ understanding of the most salient concepts that framed the new narratives during these on-course literary productions. Moreover, from a contrastive view of a second language/culture different from that of the original extract, we cannot forget to concentrate on the mental foundations of those texts as the very first online configurative steps of such new Modern English concepts as those cited above, complex concepts organizing the later evolution of Western Culture as we know it today. Normally, the teacher should perform this task at the most basic methodological introductory level, in a very simple way that will be unconditionally overwhelming for the student for a time.

In the framework of current biocultural studies of mind and language, we start from the following hypothesis: A specific conceptualization and meaning construction of abstract entities like MAN, NATURE or SCIENCE as materially, i.e., linguistically evidenced in those L2 texts, guides each student's learning process from a former enactivation of culture-specific knowledge in L1. Although it is difficult to envisage a more complex sociocognitive situation (for our students it is not only the weird experiential living of a second language but the attempt to understand the most abstract experimental texts written in the history of human thought), today we have the tools to make it easy with the interdisciplinary principles, methods and models provided by Cognitive Poetics and Cognitive Linguistics.

When back in 1999 Langacker (1999: 16) described language as "an essential instrument and component of culture, whose reflection in linguistic structures is pervasive and quite significant", he was thinking for speaking/writing (Slobin, 1991: 12) about everyday language. The literary languages of the English Enlightenment, the Anglo-American Modernism, and Postmodernism, are overtly elaborated in this instrumental sense, and the new concepts attributing new meanings to the human being in this constructivist view seem to work as primary poiesis (from Latin fabric) showing a specific human conceptual integration of linguistic mind and beauty as an experiential crosscultural and transhistorical phenomenon (Brandt, 2002: 1) of the Western civilization. This is to say that our Spanish students have to learn about Modern English society from the beginnings of our distinct Western civilization's new conceptualizations in the Enlightenment period throughout the Spenglerian decline of the West and the Poundian "Make it new!" in the Modernist period, and along novel Postmodernist metafiction. Moreover, this task has to be taken in incorporating not just new $\mathrm{L} 2 / \mathrm{C} 2$ information but hidden $\mathrm{L} 2 / \mathrm{C} 2$ meaning constructions of new knowledge: a real Gordian knot. 


\section{BRINGING IN NEW CULTURAL APPROACHES TO COGNITION, LANGUAGE, AND LITERATURE}

We here claim that a more adequate method requires attention to cultural approaches to cognition and language (Sinha 2017,2021). Current interdisciplinary cognitive theories about the pervasive figurative way human beings assemble and produce knowledge of the world at a fundamental sociocognitive level have occupied so far much academic space ${ }^{3}$. In the framework of cultural relativism, and in tune with his notion of culture as a 'textile of meanings', anthropologist Clifford Geertz (1995: 2) suggested that we have "to be satisfied with swirls, confluxions, and inconstant connections; clouds collecting, clouds dispersing. There is no general story to be told, no synoptic picture to be had. Or if there is, no one, certainly no one wandering into the middle of them like Fabrice at Waterloo, is in a position to construct them, neither at the time nor later. What we can construct, if we keep notes and survive, are hindsights accounts of the connectedness of things that seem to have happened: pieced-together patternings, after the fact." Along the same line and as result of his search for the human cognitive dynamics of mental spaces, Gilles Fauconnier observed:

Once we start paying attention in everyday life, to instantiations of connectors, frames, induced schemas, conceptual connections, and metaphor, counterfactual mental spaces ... the real world discloses far richer and more revealing configurations than our feeble efforts as linguists or philosophers have been able to produce. There is an abundance of such data that goes largely unnoticed despite its obviousness, mainly, it would seem, because it does not fit the observational categories of our established academic practice. 'Discovering' bodies of data that were staring us in the face, and yet were invisible to us (the black holes of science, the blind spots of the scientist) is a common feature of the evolution of scientific inquiry. (XXVII)

This paper is grounded in the thesis that enactive knowledge is knowledge acquired in the action of an organism in an environment (see Varela \& Maturana 2003). To enactivate an experimental literary text for the first time is a hard cognitive task in a first conceptual, linguistic, and cultural (L1/C1) environment; but if we think of this same task as situated in a teaching/learning L2/C2 context, it clearly constitutes a real cognitive Gordian knot. Its sociocognitive complexity compels us to start considering language with Jordan Zlatev (2007: 307) primarily as "a consciously supervised conventional representational system for communicative action and thought" that has to be defined as "indivisible from its use by a specific community". So, a necessary starting point in any C2 approach to this highly challenging pedagogical activity will resume all investigations from his view of language as "a central aspect of human sociocultural situatedness" (Zlatev, 2007: 326) to Sinha $(2017,2021)$. Fundamentally, Sinha places meaning at the center of the definition of culture, proposing that any human culture should be thought of as "a pattern or patterns

3 Geraerts and Cuyckens, in their Oxford handbook of Cognitive Linguistics (2008) present an excellent global state of the arts centered on current developments of Cognitive Linguistics. Seana Coulson and Barbara Lewandowska-Tomaszczyk (2005) have edited the volume The literal and the nonliteral in language and thought, which focuses on the dichotomy literal/figurative from a psychological perspective. In the wider frame of Social Sciences, Emmánuel Lizcano's Metáforas que nos piensan (2006) interestingly opens up the idea of figurativity, particularly of conceptual metaphor, as a social institution. 
of meaning ... a normative order, realized and reproduced in semiotic systems or vehicles including language, and in enduring artefacts and institutions; and enacted and renewed in social and communicative practices.” (2017: 9). Sinha (op cit.) also emphasizes some properties that are at the heart of our teaching practice, that culture can be conceptualized from three equally valid perspectives: ways of doing things (practices); ways of thinking and feeling (mental models, schemas, worldviews, ideologies, "structures of feeling"); and ways of talking (discourses). All of these perspectives have been influential in the history of thought about language and culture in different disciplines.

\subsection{Untying the Gordian Lnot in a Real L2/C2 English Literature Class in Gran Canaria, Spain}

We are here proposing an alternative theoretical framework for teaching difficult texts, a framework that does not suffer from the defects we identify in existing practice in Spain. The following pages present a 4 years teaching experience of two undergraduate courses between 2004 and 2008: "English Literature III: 17th and 18th Century" (obligatory subject for third-year students) and "Anglo-American Literary Studies II: The Art of Fiction and 20th Century Novel" (optional subject for third- and fourth-year students). Both courses are part of a four-year BA degree in English Studies (Licenciatura en Filología Inglesa) offered by the University of Las Palmas de Gran Canaria, Spain. The number of students in class runs between 50 and 70 ; about $75 \%$ are women and $25 \%$ men.

The course "English Literature III" consists of the literary study of 17 th and 18th century literature with a reading list that includes highly experimental texts from the preEnlightenment and the Enlightenment. "Anglo-American Literary Studies II" is devoted to Modernist (and pre-Modernist) fiction. The two modules, though different in content, were approached in similar ways, given that the object of study was a usage-based approach to the language (i.e. poetic and linguistic structures) as experimentally executed by the writers of those innovative literary periods at the highest level of conceptual and cultural restructurings in the evolution of English language.

Primarily, Cognitive Semantics in general resumes the key inquiries related to language and thought that the $17^{\text {th }} \mathrm{c}$. expressed in a new language that came to be known as Modern English. These inquiries where first synthesized by Locke in his Essay Concerning Human Understanding (1690). Here globally considered as an innovative branch of current Life Sciences this proto-biopoetics chiefly puts its epistemological and ontological concern in the creative imaginative nature (both physical and non-physical) of the human mind; it does so by exploring phenomena like cognition, perception, reasoning, learning, linguistic processing, etc. as prompted by textual sociocultural dynamics. Locally, since language inputs and their linguistic outputs allow reconstructing the mental or cognitive assembly that our brain makes of reality structures, the present work is instrumentally framed within a very pervasive Idealized Cognitive Model (ICM) as offered by Cognitive Linguistics: Conceptual Metaphor. Language is obviously an instrument for expressing ideas, but the novelty is that language is now conceived as a sociocognitive ability interacting with other reasoning processes; here, the elusive reasoning processes of Spanish undergraduate students of English and American Literature. 


\subsection{In-class methodological practice}

As a first step students are introduced to the primary view that from a realistic cognitive perspective of both a non-literary and a literary text, language is the gateway towards the mind as a pervasive means to construct and communicate meaning; as such, cognition can be somehow mirrored in language. Fauconnier himself asserts: "language is only the tip of a spectacular cognitive iceberg" (1999: 96). Whenever we utter speech, we operate cognitive processes of which we are not directly aware. Fauconnier continues explaining something crucial in a Literature class about $17^{\text {th }}$ century Empiricism and its previous and later textual attribution of meaning to thought and language: that the brain is quite reachable from a physical perspective, but what we can speculate about its neurobiological structure and conceptual architecture is known indirectly, through the shortage of the linguistic sign. A second introductory step is that the linguistic information should not be undervalued, because it allows us to recreate the internal cognitive processes. Students are reminded that misidentifying it after habitual literal translations into L1 break these processes. Some examples are shown first from L1, and then from excerpts in the reading list, of how linguistic forms are capable of prompting cognitive constructions. There is a dichotomy between the complexity of mental processes that construct meaning and the succinctness of language; the teacher works this out using simple ordinary Spanish examples to open the students' minds onto what is an abstraction understood as conceptual complexity expressed in simple linguistic structures. That is to say, there is a whole collection of pre-existing knowledge in the brain of humans that allow meaning construction. Here the teacher stops and invites the students for some minutes to think about the creative mind and the ordinary vs. the literary language in diverse cultures. A folk theory of language which has proved pervasive among these students would defend that meanings are enclosed within words, because what they immediately perceive when a word is uttered is a specific meaning directly assigned to it in L1, with no awareness of all the underlying mental operations in L2. At this point they are reminded from previous $1^{\text {st }} \& 2^{\text {nd }}$ year courses in Linguistics and Literary Theory that this stress on the form/meaning polarity derives from Structuralism.

\subsection{Preliminary Familiarization with Conceptual Metaphor Constructions}

In our English Literature lessons, therefore, primary emphasis was laid on a textual analysis in the cognitive direction. Those analyses were conducted by the students after some very basic formal instruction on Conceptual Metaphor Theory, understanding metaphor in the seminal sense of Lakoff: "a form of conceptual projection involving mappings or correspondences holding between distinct domains" (Evans, 2007: 136). Some activities are introduced here as a game, focused on major differences between L1 and L2; the aim is to experience metaphor as defined by Cognitive Linguistics, this is, as the construction of one conceptual field (target) in terms of the structure of another conceptual field (source). The target domain tends to be abstract and difficult to define particularly during highly emergent meaning-construction phases; this is the case with concepts like MAN, NATURE, REASON, SCIENCE, DEMOCRACY, during the Enlightenment period. Thus, we accomplish such understanding process through the use of a more concrete, physical source domain. These 
students had never heard before anything related to the fact that our embodied experiences with the physical world serve as a natural and logical foundation for the comprehension of more abstract domains because our construal of reality is mediated in large measure by the nature of our bodies. That we talk about abstract (complex) entities like LIFE and LOVE in terms of concretely experienced realities like JOURNEY, about THEORIES in terms of BUILDINGS, or about IDEAS in terms of FOOD (Kövecses, 2002: 5). This basic cognitive principle of any language sets up a playful beginning of these students' journey into such "weird" unconventional texts like Burton's Anatomy of Melancholy, Donne's "The Sun Rising”, Bacon's living Essays, Hobbes's Leviathan, and so many other experimental mentils (Guerra de la Torre, 2010:14). At this point, the teacher jumps backwards from Shakespeare to Webster in terms of looking for "the real thing" as a matter of understanding what a living system is and its relation with language/culture. The rational is that the students have already taken this class previously and thus it takes only a few minutes and 2 short excerpts as prelude to our main concern on the nature of mind and language during the Enlightenment. We pose questions like "Who do you think is more 'real' as person, Juliet or the Duchess? They immediately perceive the more chaotic text as more real Duchess and the more linear experience of Juliet being madly in love as unreal. They quickly become aware that it is the human voice and the text as a complex living system what is crucial for the observer/reader to construct a person, and not so much the ideas as isolated in axioms or ornaments. After we have read these excerpts from both texts they are invited think about the question "how can all of us perceive/be one and the same Juliet in-love while there is only one Duchess of Malfi?" This contrastive first experiential approach has attested the pedagogical usefulness of showing language as a matter of thought (a living system), as the real thing in literature as in life. These warm-up pre-Enlightenment exercises are followed by a very productive comparison in terms of life between the linearity of Spenser's poems and the nonlinearity of Donne's. Progressively during the semester, each text triggers in every student a waterfall of very trivial (but rigorous) questions prompted by their first awareness of what concepts are in relation to language and culture, and of how curiously linguistic representation diversely structures them. The outstanding capacity of our students for any empirical interactivity promoted by their technological environment starts to be visible in their otherwise unconscious interpretative task. Only after this first real narrative familiarization/prompts, they started reading excerpts from Bacon, Berkeley, Locke or Hume. They exhibited a fundamentally different understanding of what English language, literature, and culture is, even when they are not still prepared to think or write coherently on this new knowledge. But their eyes were now open into the new way to understand not only these L2 texts, but the wider field of the Humanities that understands cognition as action.

\subsection{Introducing the Theoretical and Methodological Foundations}

In the following paragraphs we will explain how the teacher provides the students with a very general view of the theories and methods being implemented in class. Of all recent approaches to language and thought in general and to figurative language in particular, Cognitive Poetics and Cognitive Linguistics supply the primary foundations to develop a realistic experiential on-line analysis of meaning construction and of knowledge of the 
World construction that we see as much needed in Tertiary Education studies of literary texts. Particularly, the new theory of metaphor (originally developed in Conceptual Metaphor Theory by Lakoff \& Johnson in their seminal work Metaphors we live by) differs from the old one that conceived of it as a matter of language, as a rhetorical figure with main 'ornamental' or 'optional' functions. Throughout the history of language and linguistics, metaphor has long been a marginal subject of study. Metaphor has been regarded just as a decorative device of literary discourse. This view of metaphor as an embellishing figure of speech was typical of the ancient rhetoricians like Cicero and Aristotle but has survived well until the twentieth century.

In the cognitive-linguistic view, metaphor has been considered a matter of thought because from advances in sciences like neurobiology or cognitive psychology it was found out that metaphor like metonymy, synaesthesia, and other formerly considered "figures of language" are fundamental cognitive processes basic to the human capacity for meaning construction in general.

Cognitive Studies of Language explore how the human being categorizes and conceptualizes the world, processes that are previous to the occurrence of a language. As such, these studies are really helpful in our understanding of English literary texts. Basic findings activated in our classes are well-known cognitive principles like: (1) the mind is inherently embodied, (2) thought is mostly unconscious and (3) abstract concepts are largely metaphorical (Lakoff \& Johnson, 1980: 3). These interdisciplinary keys invite the students to rethink and redefine their popular approach to literature. A handout with the chart below, with information adapted from Kövecses (2002: vii-viii) offers illustrations to students of primary differences between the old and the new view of metaphor:

\begin{tabular}{|l|l|}
\hline The traditional view of metaphor & The new view of metaphor \\
\hline $\begin{array}{l}\text { Metaphor is a property of words. It is a } \\
\text { linguistic phenomenon }\end{array}$ & $\begin{array}{l}\text { Metaphor is a property of concepts (it is } \\
\text { conceptual in nature) and not of words }\end{array}$ \\
\hline $\begin{array}{l}\text { Metaphor is used for some artistic and } \\
\text { rhetorical purpose }\end{array}$ & $\begin{array}{l}\text { Metaphor is used to better understand } \\
\text { certain concepts and not just artistic and } \\
\text { aesthetic purpose }\end{array}$ \\
\hline $\begin{array}{l}\text { Metaphor is based on a resemblance } \\
\text { between the two entities that are compared }\end{array}$ & Metaphor is often not based on similarity \\
\hline $\begin{array}{l}\text { Metaphor is a conscious and deliberate } \\
\text { use of words that only artists have got }\end{array}$ & $\begin{array}{l}\text { Metaphor is used effortless in everyday } \\
\text { life for ordinary people not just geniuses }\end{array}$ \\
\hline $\begin{array}{l}\text { Metaphor is a figure of speech we can } \\
\text { do without, is not an inevitable part } \\
\text { of everyday human communication, } \\
\text { let alone everyday human thought and } \\
\text { reasoning }\end{array}$ & $\begin{array}{l}\text { Metaphor is an inevitable process of } \\
\text { human thought and reasoning. It is } \\
\text { pervasive both in thought and everyday } \\
\text { language }\end{array}$ \\
\hline
\end{tabular}

Figure 1. Different views of metaphor 
What is new in the conceptual metaphor theory as a model to apply to the study of a literary text is that it is a comprehensive, generalized, and empirically testable theory with the means of new technologies like Neuroimaging or Synthetic Biology; as such, it has become a most outstanding contemporary approach to Literary Studies from the 1990s, centered on dynamics of sense making through meaning and knowledge of the world construction that allows us to be aware of the complex way writers think (see Freeman 2007; Guerra 2013).

As one of the main targets of our courses is getting as close as possible to any crosslinguistic and intercultural evidence about the writer's real, living thoughts, a pedagogical strategy that also frames the artful efforts of thinkers/writers in these experimental literary periods is set forth. To do this, we applied the most basic conceptual mappings of cognitive metaphors to start unmasking the way writers/thinkers could have experienced the highly changing reality of their everyday lives from the 17 th to the 20th century in England and North America. The main target was to prompt our students' awareness of the cognitive, i.e., biocultural differences with the way they think about main concepts like UNDERSTANDING, EMPIRICISM, TIME, - particularly abstract for Spanish tertiary education students from a first unfit schematization as concrete dictionary meanings in L1, during the on-course reading process. Just being aware for the first time of this contrastive conceptual and linguistic typology in English and Spanish cultures notably implemented our students' competence as readers and performance as C2 observers and L2 users.

\section{ADVANTAGES OF COGNITIVE THEORIES IN ELS IN SPAIN}

This enactment of our classes applying natural, very basic, cognitive methodology is framed in Biopoetics in order to extend the cognitive poetic, semiotic, and linguistic tools to other traditional Poetics theoretical knowledge about the importance of non-linguistic material elements in the construction of meaning and of knowledge of the world (Dolezel, 1990). At this moment students intuitively understand why Literature is not just a question of steadfast ideological rationality so that they begin to explore the texts in search of signs with other pragmatic functionalities to make sense of them as real. The notions of fiction and reality prompt a basic discussion among students that the teacher uses to bring about contemporary expressions related to this potential dualism. It was observed that the way they understand culture, language or text begins to change. It is vital that the continuous evaluation criteria allow them to make mistakes out of counterintuitions. This is precisely what distinguishes this approach from the usual introspective hermeneutical one guiding the student to quick, superficial rational observations most of the times ideological and L1/ C1-specific while reading $\mathrm{L} 2 / \mathrm{C} 2$ texts.

\subsection{Biopoetics. Introducing a New Vision of Poetics As Dynamic Action}

In Literary Studies, Poetics has traditionally offered a multidisciplinary approach to linguistic phenomena. Poetics must be understood here from its original etymological sense. In Greek, poiesis meant 'creation, production, action'. Poetics, in this sense, is complementary to traditional Hermeneutics. In the literary lessons taught by the teacher, priority was thoroughly given to the former. Whereas Hermeneutics, the widely-used 
approach in Literature classes, searches for the meaning of texts (trying to reply to the question "What does this L2/C2 text mean when enacted by a L1/C1 student?"), in Biopoetics the crucial question is "How does this text mean?" or, synonymously, "What are the mechanisms that make it possible for a text to mean so many different things for so many different readers?" (Guerra et al., 2009: 97-98). This method proved much more creative both for the students and for the teacher.

Up to now, Literary Studies and its pedagogical strategies have excessively concentrated on the L1 culture-specific interpretational possibilities of texts, thus ignoring the apparatus that effectively generates meaning. Our undergraduate students have been taught how to examine not exclusively the particular meanings of the literary works but most importantly the dynamic processes that create the new literary and cultural outstanding concepts of the periods under scrutiny. For instance, as a warm-up activity, contemporary sentences such as "Years rush by like water over rocks polishing us to beautiful perfection" (Anonymous) were used to develop students' ability to recognize how the construction of concepts works. Once the sentence was read, we would work out through active participation the major concepts mentioned in the previous utterance (namely TIME and BEAUTY). Then we would search for Conceptual Metaphors used to build those concepts and thus generate meaning such aS TIME IS A RIVER, PEOPLE ARE ROCKS, LIFE IS A JOURNEY, PURPOSES ARE DESTINATIONS, BEAUTY IS DEATH/ETERNITY to name a few highlighted and hidden metaphorical projections. Once the process was understood and completed we would work with representative 17th and 18th-centuries texts whose complexity and difficulty was higher (e.g. John Donne's poem "Uprising Sun" and his Meditation, "Devotions upon Emergent Occasions"). Apart from literary texts proper, we parenthetically used other instances of discourses (advertising language, political speech, etc.) to apply the cognitive method in the various class sections as an activity to motivate students to participate and comprehend the methodology, which in the end proved to be highly valuable as seen orally in class and as initially shown in a written corpus of more than 200 assignments and final papers executed during 2005-2011. Therefore, Biopoetics and Cognitive Semiotics, Poetics, and Linguistics seem to be an excellent methodological framework to the unifying study of texts from different languages, cultures, times, and genres in diverse cultural communities. As such, it allows the teacher to invisibly unknot the students' entire misunderstanding of evolutionary literary times and genres. Nowadays, Biopoetics extends the fields of Cognitive Linguistics and Poetics in a higher dynamicist way implementing the reality that the only difference between natural language and artistic language is the degree of complex conceptual experimentation triggered by the artifice in observers/readers from diverse cultures (Guerra, 2016).

\section{TYPES OF INTRODUCTORY TASKS IN THE ELS CLASS}

We would like to present two activities used in class in order to introduce the applicability of the models developed throughout the courses. As a warm-up, we asked students to think about a paragraph that was not part of the syllabus reading material to avoid any fear to consider it a possible part of later assignments of exams. The following is an example taken from Oliver Wendell Holmes's The Autocrat of the Breakfast-Table (1857: 93): 
I find that the great thing in this world is not so much where we stand as in what direction we are moving: To reach the port of heaven, we must sail sometimes with the wind and sometimes against it- but we must sail, and not drift, nor lie at anchor.

In the light of the previous excerpt, students were expected to perform these foregrounding tasks: "How does this sentence construct the concept of LIFE?" "What concrete entity is being used to construct the concept?" and "Underline the linguistic expressions used to argument your answer". To these questions, we could choose one answer to direct the student's reading (that the passage constructs the concept of LIFE with the basic idea of a PATH); we could also use more indirectly examples from real life in L1 to press what we call their ear for concepts (students produce particularly smart answers here based on real life in January like "la cuesta de Enero"/"the January slope"). The motion schema on a path underlies the concept of LIFE as JOURNEY. Image-schemas structure many of our abstract concepts metaphorically. The concrete domain used is that of a JOURNEY. The linguistic expressions chosen are this world, we stand, what direction, and we are moving.

Kövecses's volume (2002:3) also offered interesting literary quotes and analyzes that we explored in our classes during this first warming-up phase. Here is an example:

People might say that they try to give their children an education so they will get a good start in life. If their children act out, they hope that they are just going through a stage and that they will get over it. Parents hope that their children won't be burdened with financial worries or ill health and, if they face such difficulties, that they will be able to overcome them. Parents hope that their children will have a long life span and that they will go far in life. But they also know that their children, as all mortals, will reach the end of the road.

Reading this fragment, students are asked to find out those linguistic expressions that have to do with the concept of LIFE; then they have to investigate in terms of how and why the abstract concept LIFE takes partial structure from different concrete concepts to be understood. Kövecses himself replies that expressions such as to get a good start, to go through a stage, to get over something, to be burdened, to overcome something, a long life span, to go far in life, to reach the end of the road used to speak about life derive from the way we speak about journeys. It seems that we use the domain of JOURNEYs to understand broad and abstract concepts of LIFE in an attempt to comprehend it.

In this first stage, the teacher tried to avoid excessively technical terminology to account for these weird linguistic phenomena that pervasively fill our highly abstract texts. We wanted our students to have a clear first picture of what are the superficial metaphorical relations between concepts in order to understand the way authors could produce so much new structural devices at all linguistic levels; we then basically related this intense emergence process to the crisis of the period in all aspects of personal and social life. The aim was to awaken students' awareness that thinking about abstract concepts like LIFE, is facilitated by structuring as the more concrete concept of a JOURNEY, and that here is where metaphor comes into scene. Literary texts are sets of conceptual projections like these at different levels of compositional complexity. The more vital is the human experience represented (i.e. UNDERSTANDING, KNOWLEDGE, etc. as highlighted in the Enlightened texts), the more complex is the conceptual structure activated and evidenced on a linguistic basis. Try to define terms such as love, society, politics, education, mind, time, desire, religion, and 
death. Hard work, isn't it? We tend to explain abstract or intangible concepts in terms of material or tangible ones. Student's playful attitude is required here as didactic recreation.

\subsection{A Sample Cognitive Analysis of a Literary Fragment}

Having previously dissected hazardous examples of introductory activities as warmers or fillers, the core of the class was a more comprehensive analysis of literary fragments (full title page, full dedicatory, and extract from the main text) taken from a selection of first-edition-works compiled by the teacher throughout her teaching career. We would like to describe in detail the different steps involved in the process of text analysis. In this description, we will stick to one of the courses taught, English Literature III (17th and 18th centuries), given that it is more illustrative of the methodology handled by the teacher. This pedagogic rational is based on the technical (linguistic mind) unawareness of the Enlightenment writers compared to the use of visible narrative and linguistic strategies by the Modernists and Postmodernist writers.

The first step in any teaching/learning setting is to delimit the objectives that we intend to achieve. In general, we plan to describe and explain certain aspects of the repertoire of resources available to represent thought in terms of a variety of cognitive dimensions that operate in literary creation. Both in ordinary and literary English language, our students will be able to understand the interdependent relationship between linguistic form and meaning. In particular, the aim is that students can identify the new fuzziness of the key concepts as expressed in the $17^{\text {th }} \mathrm{c}$. texts and the logics of their complex dynamics of language/culture entrenchment in the 18th century literary texts, this is, that they become aware of how those concepts are alive then and now; and aware of how they have evolved till our days designing the complex-specific architecture of a Western Culture that is presently living in the way they think/speak/write about real English C2 abstract entities from there Spanish $\mathrm{C} 1$ for instance. An example that proved particularly captivating for these undergraduate students was contrasting the conceptual construction of MELANCHOLY as lived by Burton on Anatomy of Melancholy to DEPRESSION as a pervasive concept in their 21 st century lives easily experienced at the conceptual and linguistic level both in L1/C1 and L2/C2.

As far as the schedule is concerned, this basic introductory project has been accomplished in one term. The pragmatic use of the reader provided by the instructors at the beginning of the semester sets the nucleus of the teaching and learning process in each text as a mentil (living fossil) that can be thoroughly inspected. On the one hand, from the philological and linguistic perspective, the analysis of individual texts will provide access to everyday human mechanisms of meaning construction and concept building. On the other hand, exploration of such texts will allow students to search for the real cultural and sociohistorical background of the authors and to rethink information learned in other classes like "Cultural History", "History of the English Language" of "Other Literature in English".

\subsection{Tasks and Activities}

Now we will provide an account of the necessarily very simple steps, tasks, and activities developed in our practical classes. Students were expected to engage in a number 
of activities, all of them part of the continuous evaluation, namely: the writing of a summary, cooperative work in groups, and a final paper which they should prepare individually at the end of the term.

a) Summary. In the pedagogical experiment conducted in the English Literature class, it was central that students knew the basics of the analytical tools with which they were asked to explore each text. We used a selection of chapters from Kövecses's Metaphor: A Practical Introduction (2002). The 60 students in class were distributed into groups of 6 students. Each group read one chapter and early performed a 10 minutes oral presentation using any excerpt from the Reader list as example of the chapter's content. Consequently all students have quick access to the complete introduction to metaphor that they afterward can consult for the writing of the final essay. As homework all students had to submit a one-page summary of notes taken during the presentation of each chapter completed at home with everyday L1 examples for each conceptual structure. This mostly automatic task had a double purpose. First, it was intended as a straightforward activity of extracting main ideas about the way we metaphorically project conceptual structure between different domains. Second, the document could serve as a guide for the completion of the students' final paper. By doing this, students would not only get the necessary information about the instruments of analysis. More importantly, they can also take advantage of the opportunity to ask the teacher possible questions or doubts they have in relation to the contents of such chapters. After summarizing and drawing relations between the 10 chapters most students show up a clear improved ability for language inquiry, both in L1 and L2.

b) Class work. In a different session, the teacher suggests reading one of the literary fragments from the booklet. We prefer this to be done in class, not as homework, because we wish that students get involved in collaborative work of meaning construction and creation of situated world knowledge. Here the teacher uses "Meditation IV: The physician is sent for" (John Donne, Devotions upon Emergent Occasions) to exemplify the steps of this task.

In small groups (6 people maximum out of a class of 60), students read the selected passage and individually underline those linguistic expressions which they find to be relevant or conceptually salient and that contribute to the gist of the fragment. For example, man, world, God, giant, bodies, creatures, firmament, orb, etc. At this point they choose nouns almost exclusively, still unaware of the semantic importance of phonetics, grammar or syntax, as shown for example in an indefinite article like "a" in "a little world;" or in the semi-colon, in the repetition of "little", etc. These expressions appear in the first paragraph of the text they are analyzing and which we reproduce below:

It is too little to call man a little world; except God, man is a diminutive to nothing. Man consists of more pieces, more parts, than the world; than the world doth, nay, than the world is. And if those pieces were extended, and stretched out in man as they are in the world, man would be the giant, and the world the dwarf; the world but the map, and the man the world. If all the veins in our bodies were extended to rivers, and all the sinews to veins of mines, and all the muscles that 
lie upon one another, to hills, and all the bones to quarries of stones, and all the other pieces to the proportion of those which correspond to them in the world, the air would be too little for this orb of man to move in, the firmament would be but enough for this star; for, as the whole world hath nothing, to which something in man doth not answer, so hath man many pieces of which the whole world hath no representation. Enlarge this meditation upon this great world, man, so far as to consider the immensity of the creatures this world produces; our creatures are our thoughts, creatures that are born giants; that reach from east to west, from earth to heaven; that do not only bestride all the sea and land, but span the sun and firmament at once; my thoughts reach all, comprehend all.

Instrumentally, a literary analysis is always a linguistic analysis, that is to say, an examination of the linguistic elements, properties and relations at all levels of language: prosodically, orthographically, phonetically, morphologically, syntactically, semantically and pragmatically, given that all these levels of language definitely contribute to the meaning construction dynamics of a text, as anatomy contributes to physiology, and both to biology. Nevertheless, in the Literature class, there seems to be a widely spread tendency to go directly to the ideological load of the text, i.e. to a kind of unreal semantics of the text mediated by the interpretation of the teacher, of the literary critic, of the text commentator. And narrative meanings are incongruently enactivated by the students only at a lexical-semantic level that is partially processed in L1. This tendency is, in fact, a visible product of a decontextualized hermeneutical perspective that has pervaded the scarcely stimulating Literature class for many years in Spain, a class that has traditionally been graded out of a scary one-shot final exam of circumstantial literary and historical information learned by heart.

The tools provided by Cognitive Poetics and Linguistics have helped us to change the focus of our Literature classes into a natural experiential, biopoetic one, allowing the text to be an on-line intercultural reality prompted by the linguistic constructions and the semantic construals derived from the selected L2 lexicalizations. Each text becomes real as an open adaptive system (Hayles 1991) because we do not restrict it to any mediated forced interpretation but let its global literary conceptualizing narratives self-organize in the minds of the students from a guided look at its local linguistic constructions. In the framework of this didactic enactivity, these pragmatic tools facilitate the comprehension and further integration of the regular contextual descriptive topics taught in any ELS class. Once they have identified the linguistic expressions, in the next step, students are asked to write a list of the concepts to which such expressions refer to directly or indirectly. For instance, the words veins, bones and muscles refer to the concept of HUMAN BODY (note that not only the concept but also the word body is present in the text); terms like sea, land, river, hills, stones, earth... have to do with the idea of NATURE; man, creatures, dwarf, giants refer to LIVING ORGANISMS; or, firmament, heaven, sun, air, orb, star refer to CELESTIAL BODIES. Students thus gain consciousness of the fact that natural on-line framing is crucial to understand not only L2 lexical-semantic but narrative discourse and literary texts abstractions. This method brings fun into the class and students start a sort of natural competition based on who can find the foregrounding projection first. At this point they are invited to practice this exercise outside the class in everyday situations in $\mathrm{L} 1 / \mathrm{C} 1$ to enhance their competence as readers also of $\mathrm{L} 2 / \mathrm{C} 2$ texts. 
Next, students will classify the linguistic expressions and concepts in categories through a diagram. At this point, it is essential that students can recognize the different levels of meaning construction: (i) metaphorical linguistic expressions or lexicalizations, (ii) the concepts or domains to which the previous linguistic expressions refer explicitly; technically speaking, the 'source domains' of the metaphorical projections; and (iii) the concepts implicitly constructed on the basis of the former domains, called 'target domains' of the metaphors. (After the summary and oral presentation tasks, the students are invited to creatively think at home in the L1 constructions of the L2 concepts explored in class.) The diagram is traditionally known as "conceptual map" (Rué, 2009: 178). Terminologically speaking, this label "conceptual map" should not be confused with the figures that Cognitive Theories use to represent the conceptual mappings (or projections) of cognitive metaphors. Retaking the text that we are examining, we could graphically represent the hierarchy of relations established between the concepts and the linguistic data only at the most basic local level of a dissipative structure (Guerra, 1992); the rational for this is that fully understanding it as a complex adaptive system requires an expertize as cognitivist and an experience as reader that is not the object of our undergraduate philological classes. See Figure 2 below:

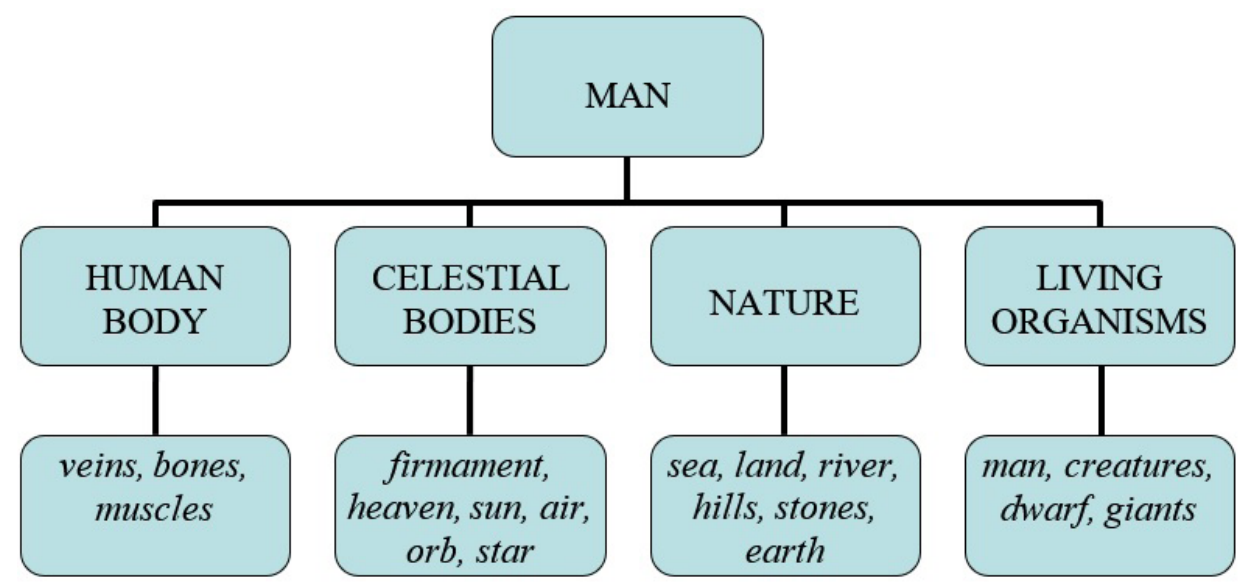

Figure 2. Conceptual map

Finally, after all this knowledge has been coherently organized, students will draw the metaphorical projections from the source to the target domain in the type of diagram conventionally used in Cognitive Linguistics. The central concept in "Meditation IV: The physician is sent for" is MAN, which is mainly construed through the notion of WORLD. Note that the concept of WORLD embraces the ideas of HUMAN BODY, CELESTIAL BODIES, NATURE, LIVING ORGANISMS, etc. In other words, the conceptual domain of WORLD gives structure and content to the idea of MAN. The diagram that students would be expected to elaborate should be something close to Figure 3: 
Source domain: WORLD

Target domain: MAN

\begin{tabular}{|c|c|}
\hline creatures or giants & $\rightarrow$ thoughts \\
\hline parts or pieces of the world & parts of pieces of a man \\
\hline rivers & veins \\
\hline hills & muscles \\
\hline stones & bones \\
\hline
\end{tabular}

Figure 3. Representation of metaphoric mappings in cognitive theories

All the previous words (creatures, giants, thoughts...) are mentioned in the fragment. The student's job is basically a process of identification and classification of the concepts being constructed and the linguistic material triggering those conceptualizations. This marks the end of the pedagogical action. By the end of the Literature class, students will have learned to pragmatically compare and analyze the linguistic evidence and to summarize all that knowledge through graphical representations. It's only after this that they are asked to interpret/criticize the text adding the new more phenomenological, cognitive approach to the regular traditional incongruent reading. The final papers results demonstrated, as illustrated below, a higher control of the $\mathrm{C} 2$ text conceptual reality and also of personal creativity at all levels of contextual interpretation by the students, and an improved critical expression in L2.

c) Final paper. In the final paper, students were expected to choose a text from the Reader. In class we had only seen short extracts from those texts. In this essay, students had to carry out a textual analysis on their own. In this way, the teacher could evaluate up to what extent the students had advanced in the understanding of literary texts through conceptual metaphor. The final project served as a consolidation of all the practice and group work done throughout the term. This final paper was a demonstration of a Spanish student's ability to carry out a philological understanding of a L2/C2 literary text individually. Furthermore, it has proved to be an inspiring challenge for our students, since it was the first time to face such an analysis, motivating a more realistic personal activation of new cultural constructions. Each student can use a tutorial with the teacher to improve it during the composition. The format of the final paper consisted of: (i) a brief introduction presenting some personal details about the author and the sociohistorical context in which the work was written, (ii) a basic local linguistic and metaphorical analysis of the text chosen by the student, and (iii) a conclusion in which the student produces a global interpretation of the text on the basis of the previous analysis and relates it to the descriptive traditional literary information (theory, history, etc.) of the period taught as seen in class through powerpoint presentations. Section 1 of the 
papers varied depending on the text selected. However, we can reproduce the core analysis of section ii performed by one of our students ${ }^{4}$ as example of the extent to which their capacity to start dealing with structural conceptual complexity as part of everyday thought, of everyday biocultural life, increases:

Fragment: "He may stand like an isthmus betwixt the two encroaching seas of arbitrary power, and lawless anarchy" (John Dryden, All for love, 1678).

Analysis: Dryden compares the political tendencies of anarchy and authoritarianism to the sea. In this case, an element of nature is used as a source domain to refer to those two political options equally dangerous for the British people (complex political systems). The characteristics of the sea (wildness, powerful and uncontrolled force) are used by Dryden to refer to the dangers of both political options. In a metaphorical extension, Dryden signals that the King may be the isthmus between them, the "safe" land which should not be affected by those seas. In these conceptual metaphors used by Dryden, the mappings may be the following:

\begin{tabular}{|l|l|}
\hline SOURCE DOMAIN & TARGET DOMAIN \\
\hline the sea & anarchy or authoritarianism \\
\hline the isthmus & the King \\
\hline the mariners & the English people \\
\hline
\end{tabular}

Figure 4. Mappings in Dryden

In this teaching experiment, the assignments' results were increasingly satisfactory year after year as the teacher became more and more expert to handle it. The students who were constant, read the corresponding chapters, attended the lessons, participated in class, and engaged in teamwork produced more than reasonable pieces of work. Their final papers showed a great understanding of the meaning-construction processes that become active in the literary text and most of them expressed how much they enjoyed the cognitive methodology in their literature classes, although students themselves acknowledged their difficulty in getting used to that new and mostly counterintuitive methodology.

A minority of students wrote relatively poor papers because, although they handed in their summaries on a regular basis, they did not consider class attendance to be important so they missed the opportunity to practice and really participate in group work. This situation made a substantial difference in their final exam, even menacing their pass mark.

\section{CONCLUSIONS}

The traditional principles and methods, as described in Occidental Poetics (Dolezel 1990) and as developed in current Cognitive Poetics, and the more dynamicist framework of Biopoetics, together with the models from Cognitive Linguistics, have allowed our students to theorize and dissect the linguistic material in a trouble-free search for real conceptual

4 We reproduce the work done by Míriam Santana Rivero, third-year student of English Studies from the University of Las Palmas de Gran Canaria (2008/2009). 
constructions derived from any type of text. In other words, they have been allowed to turn L2/C2 texts into 'real things' as part of their cross-cultural lives. The observers enact each text, in these circumstances, as a living fossil (called mentil in Guerra, 2009: 14) that registers both the physical and the non-physical evolution of human living mind and living culture; it crucially displays as linguistic material that allows human conceptual foundations to be explored scientifically. Just as an intern in a laboratory analyzes chemical substances or investigates bacteria microscopically, the purpose of our Literature classes is that students of Philology can be aware of thinking processes in a different culture (C2) pragmatically activating the linguistic components of a L2 text as scratch out of which life can be chaotically created in a self-organizing process of meaning construction and knowledge evolution that integrate themselves as active agents. This text, therefore, has to be realistically approached as a complex adaptive system. Moreover, this approach is evocative of the etymology of philology as intense emotive-cognitive activity: 'love for letters', 'love for the word', 'love for language'; from Greek philos- 'love, study' and -logos 'word, speech'). We wish for our students to learn how to read literature in general and a literary text in particular; we wish for them to start an inclusive approach to science through the new Cognitive Humanities showing them how to scrutinize the linguistic human phenomena in terms of non-linguistic natural phenomena in order to identify the culture-specific conceptual living system underlying the linguistic artificial machinery of the text; we wish for our students to feel like shaping-individual part of this new social universe that is growing up in Europe and the rest of the World apparently as unexpectedly as they grow up. This active re-conceptualization of Humanities, Philology and of Poetics as human poiesis is totally compatible with the principles of the new alliance between Natural Sciences and Human Sciences (Prigogine \& Stengers, 1990) and with the future of the European Space for Higher Education (ESHE); it also confers Humanities and Literature the scientific prominence that has disappointingly been denied so far. This novel realistic view on the Humanities makes us participate in their philological, ontological and cultural contents as creative agents and comes to reinforce our innovative pedagogical goals as proposed in Guerra (1998: 57). These preliminary teaching experiments and their creative outcomes during the last decade have clearly shown how the highly problematic English Literature class in a non-English Spain can be renewed through the implementation of a cognitive methodology.

Interestingly, as demonstrated in class-practice and in their first and last class written essays on the same extract, the students' attitude towards this method was extraordinarily positive; our hypothesis is that their proficiency to read these texts was expanded through a very basic introduction to Conceptual Metaphor methodology. There was a mutual awareness of the validity of Cognitive Theory, manifest mainly through direct reading and active dialogue. We observed that reducing the teacher's talking time increased the students' involvement, in line with the recommendations of the Bologna Process. We also respected and encouraged silence during reflective reading as part of class sections. Participation was much promoted in class and students progressively got familiar with the analytical tools that would allow them to inspect the literary text in a completely novel way. In conclusion the teaching strategies used have proved to be considerably successful. Students learnt to read literature through a different lens; as shown in their oral and written productions their proficiency largely improved on the cognitive basis of a new conception of the literary 
mind as developed by Mark Turner $(1991,1996,2006)$ paradoxically still mostly invisible for them at a technical, conscious, level.

We must admit that teaching in Spain so far has typically followed the Transmission Model of Education. In the light of the experimental classes that we have conducted with our L2 Literature students, we believe that we have acted in accordance with the demands of the Bologna process and the European Space for Higher Education.

In our approach to Literature through Cognitive Poetics and Linguistics, we have challenged the traditional pattern of Literature teaching in our Spanish universities. On the basis of our students' knowledge of the subject, we have established connections between such knowledge and new reading strategies, reconsidering the usefulness of traditional and new ways to activate on-course text analysis as a social group in class. The teacher plays the role of a dynamizer and a stimulator whereas the student becomes a real thinker in the exploration of the literary text, continuously tracing analogies between the lives narrated in the texts and their own lives; this has lead to a situation of mutual enrichment. Foundationally regarding cognition as embodied, situated, distributed, synergic and dissipative human action (Guerra, 2013) we intend that L2/C2 classes can be an opportunity for creative collaborative work through co-operative meaning construction. Both for teacher and for students, it is crucial to assume that the creative component of this process relies not on epistemological certainties and closed information but on crisis and open meanings that we all have to experience as the real thing in the counterintuitive social learning process and never as individual academic failures.

Therefore, by means of this constructivist orientation in class, we allow the on-line emergence of thought and facilitate spontaneous creation of real knowledge. The "emotionalpersonalizing" approach helps the teacher and the students to work in a more congruent and cohesive way, breaking the hierarchy and producing a feeling of mutual learning. A central idea is that of interaction in a secure atmosphere of creative-chaotic output. We have experienced that this might be the only situation in which the Poetic strategy is prioritized, since the teacher is no longer that authoritative unidirectional conductor of an established linear meaning, duplicating cultural patterns of ideological thought and action. Otherwise, we are just repeating the biased hermeneutical interpretation that has been prototypical in the L2 teaching English Literature classes for years and years in Spain, producing so much positive entropy in the L1 learning system as to make it really difficult to make our educational task really new. I claim that it has been dramatically forgotten for many years after the rise of Cognitive Semantics in general, and it is predominantly the case today, that negative entropy in Nature and Culture is the only key to creativity, learning, and evolution.

\section{REFERENCES}

ACHARD, M. \& NiEMEIER, S. 2004. "Cognitive linguistics, language acquisition, and pedagogy". In Achard \& Niemeier, eds. Cognitive linguistics, second language acquisition, and foreign language teaching. Berlin: Mouton de Gruyter. 1-12.

Bernárdez, E. 2007. “Synergy in the Construction of Meaning”, Ed. M. Fabiszak Language and Meaning. Berlin: Peter Lang. 15-39. 
BERnÁRDEZ, E. 2008a. “Collective Cognition and Individual Activity: Variation, Language and Culture". In R. M. Frank et al. eds. Body, Language, and Mind (Vol. 2): Sociocultural Situatedness. Berlin/New York: Mouton de Gruyter.

BernáRdez, E. 2008b. El lenguaje como cultura. Madrid: Alianza.

Brandt, P. A. 2002. "Music and the Abstract Brain". Plaisir. The Pleasure of Art as Sensed by the Brain. The First International Conference on Neuroesthetics. UC Berkeley, California, January 12, 2002.

Bretones Callejas, C. M. ET AL. 2009. Applied linguistics now [ Recurso electrónico] : understanding language and mind. La lingüística aplicada actual : comprendiendo el lenguaje y la mente. Almería : Universidad de Almería.

Dolezel, L. 1990. Occidental Poetics. Tradition and Progress. Nebraska: University of Nebraska Press.

Evans, V. 2007. A glossary of Cognitive Linguistics. Edinburgh: Edinburgh University Press.

Fauconnier, G. 1999. "Methods and generalizations”. In T. Jansen \& G. Redeker, eds. Cognitive Linguistics. Foundations, Scope and Methodology. Berlin: Mouton de Gruyter, 95-129; 95-98.

Frank, R. ET AL. 2008. Body, Language and Mind: Sociocultural situatedness. Vol. 2. Berlin/New York: Mouton de Gruyter.

Freeman, M. 2007. “Cognitive Linguistic Approaches to Literary Studies” Eds. D. Geeraerts \& H. Cuyckens. The Oxford Handbook of Cognitive Linguistics. Oxford: Oxford University Press. 1175-1201.

GeERTz, C. 1995. After the fact: Two countries, four decades, one anthropologist. Cambridge, MA: Harvard University Press.

Guerra, J. 1998. "Hacia el siglo XXI. Acerca de los estudios de literatura inglesa en la universidad española", Atlantis 20(2): 51-68.

Guerra, J. 2001. "Simplixity and Complexity. The Topology of the Short Story and the Novel”. Short Story Journal 9(1): 92-111.

Guerra, J. 2013. "Poética Cognitiva: (Con)figurándonos lo real”. In M.A. Hermosilla Álvarez \& Calero Vaquera, M.L.. Eds. Lenguaje, literatura y cognición. Córdoba: UCOPress. 253-271.

Guerra, J. ET AL. 2009. “The Real Way We Think What They Think: New Cognitive Poetics and Linguistics in the English Literature Studies (ELS) in Spain”. ES 30: 85-103.

GUerra De La TORRe, J. T. 1992. La naturaleza creativa del tiempo en el nuevo paradigma del caos. Una relectura de T. S. Eliot. Madrid: PUC.

Guerra De La Torre, J. 2009. "What Cognitive Sciences as an interdisciplinary framework can contribute to the study of Literature in general and of Edgar Allan Poe's literary texts in particular", Eds. N. Estévez Fuertes et al. Genius and psicosis in Edgar Allan Poe. New interdisciplinary perspectives. Valencia: Universitat de València. 13-22. 
Guerra, J. 2016. "Nueva Poética para una transversalidad realista”. Revista de Occidente. Metáfora y Ciencia. Madrid: Fund. Ortega y Gasset. Vol 422-423: 32-44.

HaYles, K. 1991. Chaos and Order: Complex Dynamics in Literature and Science. Chicago: The University of Chicago Press.

Hutchins, E. 1995. Cognition in the Wild. Cambridge, MA: MIT Press.

Kövecses, Z. 2002. Metaphor: A Practical Introduction. Oxford/New York: Oxford University Press.

Lakoff, G. \& Johnson, M. 1980. Metaphors we live by. Chicago: The University of Chicago Press.

LAKofF, G. 1987. Women, Fire, and dangerous Things. What Categories Reveal About The Mind. Chicago: University of Chicago Press.

LANGaCKer, R. 1999. Grammar and Conceptualization. Berlin: Mouton de Gruyter.

Nuez-Placeres, G., Petersen C. \& Guerra, J. 2009. The transmission model of education: A Cognitive Approach. In Gómez Morón, R. et al., eds. Pragmatics Applied to Language Teaching and Learning. Cambridge: Cambridge Scholars. 427-445.

Prigogine, I. \& Stengers, I. 1990 [1979/1986]. La nueva alianza. La metamorfosis de la ciencia. Madrid: Alianza.

REDDY, M. 1979. "The conduit metaphor." In Ortony, A., ed. Metaphor and thought. Cambridge Cambridge University Press. 285-324.

RuÉ Domingo, J. 2009. El aprendizaje en autonomía en la Universidad. Madrid: Narcea.

SLOBIN, D. 1991. Learning to think for speaking: Native language, cognition, and rhetorical style. Pragmatics 1: 7-26.

SinHA, C. 2017. "Getting the measure of meaning”. In Dancygier, B., ed. The Cambridge Handbook of Cognitive Linguistics. Cambridge: Cambridge University Press. 493-497.

SinHA, C. 2021. "Culture in Language and Cognition". The Routledge Handbook of Cognitive Linguistics. London: Routledge. 1-31.

Tsur, R. 2002. "Some Cognitive Foundations of 'Cultural Programs"'. Poetics Today 23(1): 63-89.

Turner, M. 1991. Reading Minds: The Study of English in the Age of Cognitive Science. Princeton, New Jersey: Princeton University Press.

TURner, M. 1996. The literary mind. New York: Oxford University Press.

Turner, M. 2006. The Artful Mind: Cognitive Science and the Riddle of Human Creativity. New York: Oxford University Press.

Varela, F. \& Maturana, H. 2003. De máquinas y seres vivos. Autopoiesis: La organización de lo vivo. Argentina: Lumen Grupo Editorial.

Zlatev, J. 1997. Situated Embodiment. Studies in the Emergence of Spatial Meaning. Stockholm: Gotab Press. 
Zlatev, J. 2007. "Embodiment, language, and mimesis". In Ziemke, T., J. Zlatev, \& R. Frank, eds. Body, Language and Mind. Vol 1: Embodiment. Berlin: Mouton de Gruyter. 297-337.

ZIEMKE, T. 2007. The embodied self-theories, hunches and robot models, Journal of Consciousness Studies 14(7): 167-179. 